\title{
MEDIAC̣ÃO DE LEITURA DE TEXTOS DIDÁTICOS NAS AULAS DE QUÍMICA: UMA ABORDAGEM COM FOCO NA MATRIZ DE REFERÊNCIA DO ENEM
}

\author{
Ana Cristina Barbosa* \\ Nilma Soares da Silva** \\ Célio da Silveira Júnior*** \\ Luiza Renata Lourêdo da Silva****
}

RESUMO: Este estudo relata o desenvolvimento, a aplicação e a análise de mediações de leitura realizadas com turmas de terceiro ano do Ensino Médio de uma escola pública estadual em Belo Horizonte-MG. Nesse contexto, foram desenvolvidas atividades de leitura e interpretação relacionadas a textos de um material didático que aborda o tema Água, as quais propiciaram aos alunos o desenvolvimento de habilidades e competências presentes na Matriz de Referência do Enem. Percebemos, por intermédio da análise dos dados, que houve significativo avanço dos estudantes em relação à interação com os textos científicos escolares. Dessa forma, sugerimos esse tipo de mediação como uma estratégia para o desenvolvimento de habilidades de leitura e escrita de textos contendo "coisas de química" no contexto do planejamento habitual do professor.

Palavras-chave: Mediação de leitura. Habilidades. Enem.

\section{MEDIACIÓN DE LECTURA DE TEXTOS DIDÁCTICOS EN LAS CLASES DE LA OUÍMICA: UN ABORDAJE CON FOCO EN LA MATRIZ DE REFERENCIA DEL ENEM}

RESUMEN: Este estudio relata el desarrollo, la aplicación y el análisis de mediaciones de lectura realizadas con clases del tercer año de la secundaria de una escuela pública estadual en Belo Horizonte-MG, Brasil. En este contexto, fueron desarrolladas actividades de lectura e interpretación relacionadas a textos de un material didáctico que aborda el tema "agua", las cuales propiciaron a los alumnos el desarrollo de habilidades y competencias presentes en la Matriz de Referencia del ENEM. Percibimos, por intermedio del análisis de los datos, que hubo significativo avance de los estudiantes en relación a la interacción con los textos científicos escolares. De esta manera, sugerimos ese tipo de mediación como estrategia para el desarrollo de habilidades de lectura y escrita de textos que contengan "cosas de química" en el contexto del planeamiento habitual del maestro.

Palabras clave: Mediación de lectura. Habilidades. ENEM. *Centro Federal de Educação Tecnológica
de Minas Gerais, Belo Horizonte, Minas
Gerais, Brasil.Graduada em Química
Licenciatura pela Universidade Federal
de Minas Gerais (UFMG). Técnico
Administrativo pelo Centro Federal de
Educação Tecnológica de Minas Gerais
(CEFET-MG) E-mail: acb.qui@gmail.com

* * Universidade Federal de Minas Gerais,
Belo Horizonte, Minas Gerais, Brasil.
Doutora em Educação e Ciências pela
Universidade Federal de Minas Gerais
(UFMG). Professora Pesquisadora e
Coordenadora do Programa de Mestrado
Profissional Educação e Docência da
Faculdade de Educação da Universidade
Federal de Mínas Gerias (UFMG).
E-mail: nilmafaeufmg@gmail.com

** *Universidade Federal de Minas Gerais,
Belo Horizonte, Minas Gerais, Brasil.
Doutor em Educacãa e Ciências pela
Universidade Federal de Minas Gerais
(UFMG). Professor e Pesquisador na
Faculdade de Educação da UFMG.
E-mail: celiosilveirajr@yahoo.com.br
Belo Horizonte, Minas Gerais, Brasil.
Graduada em Licenciatura em Química.
E-mail: lu.louredo@hotmail.com 


\section{READING DIDATIC TEXTS' MEDIATION IN CHEMSTRY TEACHING CLASSES:} AN APPROACH WITH FOCUS ON ENEM'S REFERENCE MATRIX

ABSTRACT: This study reports the development, application and reading mediation's analysis conducted with third year high school classes of a public school in Belo Horizonte - MG. In this context it was developed reading and interpretation activities related to a courseware's text that addresses the water theme. It allowed students to develop skills and expertise present in Enem' Reference Matrix. We realized, through data analysis, that there was significant student's progress related to interaction with school's scientific texts. Thus, we suggest this type of mediation as a strategy for developing reading skills and writing texts containing "Chemistry things" in the usual teacher planning context.

Keywords: Reading mediation. Skills. Enem. 


\section{INTRODUÇÃO}

A leitura nas aulas de química é um recurso pedagógico que, normalmente, não leva os professores a reflexões sobre o seu uso. A maneira como é encaminhada em salas de aula não permite ao professor perceber as dificuldades que um aluno pode enfrentar ao longo de sua interpretação. Entretanto, para que o aluno consiga entender os conceitos científicos por meio da leitura na escola, é importante que ocorra a mediação do professor durante esse processo. Para isso, é necessário o planejamento de atividades capazes de envolver o aluno em uma interpretação mais adequada ao tema abordado. Segundo Espinoza (2010, p. 164),

A interpretação de um texto de ciências é sempre difícil para um aluno que lê para aprender um conhecimento novo. Para que ele consiga fazer uma interpretação correta, devem existir condições didáticas que facilitem esta apropriação.

De acordo com os Parâmetros Curriculares Nacionais do Ensino Médio $(\mathrm{PCN}+)^{1}$ (BRASIL, 2009), a análise e a interpretação de textos são, entre outras, competências a serem desenvolvidas pelos alunos. Além dos PCN+, a Matriz de Referência do Exame Nacional do Ensino Médio (Enem) (INEP, 2012) descreve habilidades presentes nos eixos cognitivos, importantes para o desenvolvimento do aluno. Dentre essas, citamos, aqui, as habilidades H10 e H17, presentes no Campo das Ciências da Natureza e suas Tecnologias, as quais foram foco deste trabalho, que tem como tema a mediação de leitura.

Tais habilidades descrevem que o estudante deve ser capaz de analisar perturbações ambientais, identificando fontes, transporte e (ou) destino dos poluentes ou prevendo efeitos em sistemas naturais, produtivos ou sociais (H10), além de relacionar informações apresentadas em diferentes formas de linguagem e representação usadas nas ciências físicas, químicas ou biológicas, como texto discursivo, gráficos, tabelas, relações matemáticas ou linguagem simbólica (H17). Essas habilidades foram trabalhadas a partir dos temas dos textos da apostila Água em Foco: Qualidade de Vida e Cidadania (MORTIMER; COUTINHO; SILVA, 2012), os quais foram discutidos com alunos do terceiro ano do Ensino Médio de uma escola da rede pública de Belo Horizonte. Além disso, as atividades elaboradas a partir da leitura dos textos foram trabalhadas com o intuito de auxiliar os alunos no desenvolvimento dos eixos cognitivos de domínio de linguagem (DL) e enfrentamento de situações problema (SP), presentes na Matriz de Referência do Enem (INEP, 2012).

Levando em consideração o contexto apresentado, o presente artigo tem como objetivo central investigar práticas de mediação docente que buscaram auxiliar os alunos na leitura de textos didáticos, visando ao desenvolvimento da competência de Domínio de Linguagens (DL) e ao aperfeiçoamento da competência de enfrentamento de Situação Problema (SP). A intenção era a de propiciar a esses alunos uma compreensão construída a partir do estabelecimento da relação entre as informações presentes no texto com outras fontes fornecidas para interpretação. 


\section{REFERENCIAL TEÓRICO}

\section{Leitura no processo de ensino e aprendizagem de ciências}

O tema leitura no ensino de ciências é um assunto que, embora tenha poucos trabalhos publicados em periódicos (SILVEIRA JÚNIOR, 2012), tem sido foco de pesquisas que objetivam desenvolver métodos de ensino que promovam o aprendizado dos alunos e desenvolvam habilidades de interpretação de textos relacionados ao ensino de ciências. Isso porque a

[...] leitura desempenha papel fundamental nas relações de ensino, especialmente no que se refere à aprendizagem de ciências nas salas de aula. Por isso, a compreensão de um texto não pode ser encarada como fruto da simples apreensão de significados literais, um processo de decifração, porque não lemos palavras, mas enunciados completos. Ler é atribuir sentidos a partir do que já sabemos do mundo ao encontrar um texto. Daí a importância de nos afastarmos do caráter de simplicidade normalmente atribuído por nós professores de ciências à leitura [...]. (SILVEIRA JÚNIOR, 2012, p. 14)

Francisco Júnior e Garcia Júnior (2010), trabalhando a leitura e a escrita como uma forma de aprendizagem para alunos de nível médio em um curso prévestibular, afirmam que:

Ler e escrever são habilidades a serem trabalhadas nas aulas de Ciências, visto que, muitas vezes, os estudantes são incapazes de interpretar questões de física, química, matemática etc., devido às deficiências na capacidade de leitura, o que implica, por conseguinte, nas dificuldades de aprendizagem científica da maioria da população. (FRANCISCO JÚNIOR; GARCIA JÚNIOR, 2010, p. 192)

A inserção da leitura e da escrita nas aulas de ciências se faz necessária a todo o momento, pois as atividades de pesquisa não se restringem apenas às investigações de fenômenos ou às apurações de dados. Essas habilidades se fazem presentes na etapa dos registros que vão desde a elaboração de simples relatórios às teses de doutorados. Com a Ciência na Educação Básica, isso não poderia ser diferente. Francisco Júnior e Garcia Júnior (2010) afirmam que trabalhar em sala de aula textos de gênero científico escolar contribui para a formação plena de cidadãos, pelo fato de propiciar aos estudantes um contato e interação com a ciência, um bem cultural e que deve ter acesso universal.

Em contrapartida às habilidades a serem desenvolvidas pelos alunos, Francisco Júnior (2010, p. 221) aponta dados do Sistema de Avaliação da Educação Básica (SAEB) de 2003, os quais mostram que: "[...] dos estudantes brasileiros do $3^{\circ}$ ano do ensino médio, $42,1 \%$ encontram-se no estágio crítico ou muito crítico de desenvolvimento da leitura".

Parte desses resultados pode ser atribuída à maneira tradicional como a leitura é abordada em sala de aula, sem levar em consideração o contexto históricocultural do aluno, salientando apenas para a decodificação de palavras. Observando o papel da escola como intermediária entre o estudante e a leitura, Geraldi (1984)², 
citado por Quadros, Silva D. e Silva F. (2011), aponta que a inserção da prática de leitura no ambiente escolar, como é realizada, pode ser classificada como uma simulação de leitura, pois o educando se posiciona à margem do locutor, levandose em consideração apenas a voz do autor. Assim, o exercício de leitura se restringe apenas à interpretação e à resolução de exercícios.

\section{Nossas concepções de texto, de leitura e de sujeito leitor}

Durante a leitura, entendemos que o texto deveria ser considerado o próprio lugar da interação, no sentido defendido por Silveira Júnior, Lima e Machado (2015b p. 55):

Os interlocutores - autor e leitores, sujeitos ativos da interação - dialogicamente se constroem e são construídos por meio do texto. Entendemos também que o texto é produto de sentidos autorais construídos e processo da produção de novos sentidos entre autores e seus leitores ou coautores. Assim, no texto há lugar tanto para uma gama de explícitos quanto para uma gama de implícitos, que podem ser detectáveis por meio do acesso ao contexto sociocognitivo dos participantes da interação. Ocorrem também vazios resultantes da própria incompletude dos sujeitos e dos seus dizeres. Aqui, a compreensão deixa de ser entendida como simples captação de uma representação mental ou como a decodificação de um emissor para ser uma atividade interativa, altamente complexa, de produção de sentidos. Logo, ler não é dizer o que o autor diz, nem o que eu vier a dizer sobre o que ele diz, mas enunciar o meu próprio sentido, o meu dizer diante do outro ou a respeito do outro. Para Larrosa $(2011)^{3}$, a leitura como experiência refere-se à transformação que ocorre nas minhas palavras, no meu pensamento e no meu sentimento na relação com as palavras, com o pensamento e o sentimento do autor. É uma disputa tensa de sentidos e de movimentos que visam dar acabamento estético aos discursos que se cruzaram no texto.

Para Bakhtin (2003), sentidos são respostas a perguntas. O sentido sempre responde a certas perguntas. Aquilo que nada responde se afigura sem sentido para nós, afastado do diálogo. As enunciações estão carregadas de sentidos, vez que também são construídas como respostas:

Toda enunciação, mesmo na forma imobilizada da escrita, é uma resposta a alguma coisa e é construída como tal. Não passa de um elo da cadeia dos atos de fala. Toda inscrição prolonga aquelas que a precederam, trava uma polêmica com elas, conta com as reações ativas da compreensão, antecipa-as. (BAKHTIN, 2006, p. 99)

Os enunciados de nossos estudantes, em resposta às questões que elaboramos, como no trabalho de Silveira Júnior (2012), demonstraram a emergência desses sentidos a partir da leitura mediada.

Ver e compreender o autor de uma obra significa ver e compreender outra consciência, a consciência do outro e seu mundo, isto é, outro sujeito ("Du"). Na explicação existe apenas uma consciência, um sujeito; na compreensão, duas consciências, dois sujeitos. Não pode 
haver relação dialógica com o objeto, por isso a explicação é desprovida de elementos dialógicos (além do retórico-formal). Em certa medida, a compreensão é sempre dialógica. (BAKHTIN, 2010, p. 316)

Para Brandão (2005) ${ }^{4}$, citado por Silveira Júnior (2015, p. 69), o leitor institui-se no texto em duas instâncias: uma em nível pragmático, e outra, em nível linguístico-semântico. No curso de seu processo enunciativo, todo texto "forma" seu leitor, indicando-lhe os processos de leitura, a maneira como ele deve ser lido. Por outro lado, numa direção contrária, o leitor também "conforma" o texto e faz isso de duas maneiras: orientando o autor e imprimindo sua marca pessoal. Assim, ler torna-se, então, uma atividade essencialmente dialógica que o autor trava com o leitor possível, cujos movimentos ele antecipa no processo de geração do texto e, também, como atividade de atribuição de sentido ao texto promovido pelo leitor no ato de leitura.

\title{
Mediação docente da leitura
}

Analisando o papel do professor como mediador do conhecimento, entendemos que este deve ser o responsável por oportunizar aos alunos a leitura de textos dentro do ambiente escolar. Francisco Júnior (2010) aponta que o texto deve propiciar ao educando não só um entendimento conceitual do que se aborda neste, mas deve, além disso, possibilitar uma releitura do mundo, um entendimento maior do que uma simples contextualização. Mas, para que isso seja possível, é importante repensar sobre as estratégias de leitura em sala de aula, de forma a promover situações em que o aluno possa expressar-se sobre seu diálogo com o texto, auxiliando o professor mediador na condução da leitura e nas resoluções de dúvidas emergidas durante a interpretação da obra.

Segundo Silveira Júnior, Lima e Machado (2015a, p. 638 e 651),

\begin{abstract}
Para Vigotski (1991), o outro participa de forma constitutiva nos processos de mediação de nossa relação com o mundo. A relação do sujeito com o conhecimento não é, portanto, uma relação direta, mas mediada. Para Geraldi, Fichtner e Benites (2006) ${ }^{5}$, Vigotski (1991, 2008) dá caráter social ao psiquismo humano ao ressaltar a mediação pelo ensino, pelas respostas, o que pode propiciar novas etapas de desenvolvimento. [...] De acordo com Freitas $(2010)^{6}$, para Vigotski (1991), há aprendizagem quando se internaliza o que foi vivenciado na relação com o outro. A internalização acontece a partir das significações construídas no processo interativo às quais o sujeito confere um sentido pessoal. Não significa, necessariamente, uma apropriação de conteúdos no sentido restrito do termo, como produtos acabados, definidos, mas de um processo oportunizado pelas vozes que circularam e pelas relações dialógicas entre elas.
\end{abstract}

Smolka (2000), baseando-se no que afirma Vigotski (1991) sobre o caráter e a função da mediação do signo, diz a nós que encontramos ali a explicitação de dois aspectos cruciais, que vão permear e fundamentar o seu e também o nosso trabalho: a dimensão discursiva (mediação pela "palavra") e a dimensão pedagógica (mediação pelo "outro"). Para a autora, essas formas de mediação 
marcam a atividade mental do indivíduo no sentido de que seus modos de agir e de pensar estão profundamente enraizados no contexto e impregnados na/da dinâmica sociocultural.

Concordando com Geraldi (2010), no sentido defendido por Silveira Júnior, Lima e Machado (2015a), assumimos como práticas de mediação de leitura aquelas por meio das quais o professor auxilia o estudante em seu desenvolvimento: o professor passa da situação de leitor-corretor para a de mediador do processo de aprendizagem e, por consequência, torna-se coenunciador dos textos produzidos pelos alunos a partir de suas leituras. De acordo com esse autor, dizemos que a compreensão do texto didático de ciências também será mais rica à medida que o professor, como mediador, conseguir "ampliar os contextos", fazer emergir "mais vozes" do que aquelas que podem ser imediatamente identificadas nos enunciados.

\section{METODOLOGIA}

Alguns documentos de apoio para o professor citam a análise e a interpretação de textos como habilidades importantes a serem desenvolvidas pelos alunos durante o percurso escolar. Como exemplo desses documentos, temos a Matriz de Referência do Enem (INEP, 2012). De acordo com a Matriz, um dos eixos cognitivos a ser trabalhado com os alunos é o domínio de linguagens, sendo essa competência mais bem-explicada por meio da habilidade H17 do Campo das Ciências da Natureza e suas tecnologias, que, semelhante à competência de domínios de representação presente nos $\mathrm{PCN}+$, pretende que o aluno tenha a capacidade de relacionar informações apresentadas em diferentes formas de linguagem e representação usadas nas ciências físicas, químicas ou biológicas, como texto discursivo, gráficos, tabelas, relações matemáticas ou linguagem simbólica. Segundo Flôr (2009, p. 218),

\footnotetext{
O novo ENEM (Exame Nacional do Ensino Médio) requer dos estudantes habilidades que estão fortemente ligadas a uma superação da visão instrumental da linguagem, pedindo que se estabeleçam relações entre textos e saindo do contexto da memorização no que se refere às ciências exatas.
}

Pensando nesse aspecto de incentivar a leitura que supera a visão instrumental da química como uma ciência exata, selecionamos textos da apostila Água em Foco: Qualidade de Vida e Cidadania (MORTIMER; COUTINHO; SILVA, 2012) para fazer parte de atividades e discussão com os alunos em sala de aula.

O projeto Água em Foco leva em consideração as relações entre Ciência, Tecnologia e Sociedade (CTS) para a discussão de conteúdos químicos. Segundo Santos e Schnetzler (1996, p. 29), "a função do ensino de Química deve ser a de desenvolver a capacidade de tomada de decisão, o que implica a necessidade de vinculação entre o conteúdo trabalhado e o contexto social em que o aluno está inserido".

Em um primeiro momento, solicitamos aos alunos que respondessem a um questionário com o objetivo de identificar as dificuldades que os estudantes 
enfrentam ao ler textos relacionados à química. As questões presentes nesse questionário foram elaboradas tomando como base a experiência das professoras da disciplina Estágio e Análise da Prática Pedagógica da Faculdade de Educação da Universidade Federal de Minas Gerais (FaE/UFMG), durante o acompanhamento de estagiários em escolas da rede pública de Belo Horizonte, quanto ao uso dos livros didáticos disponibilizados aos estudantes. Com base nos resultados dos questionários, elaboramos um teste-piloto com um texto "Petróleo: Fontes de Combustíveis e de Matérias-Primas", presente no livro didático dos alunos (CANTO; PERUZZO, 2006), para a validação da sequência de atividades proposta.

Nesse teste-piloto, a mediação era realizada pela leitura individual dos estudantes. Na etapa desse processo, a leitura individual é parte da intencionalidade docente mediadora de leituras presente nesse processo quando visto de forma integral. Consideramos a mediação de leitura um processo como um todo, que inclui o antes, o durante e o depois da(s) leitura(s) feita(s). Ao finalizarem a leitura, eram discutidas com os alunos as possíveis dúvidas de interpretação e, caso não houvesse dúvidas, o professor mediador argumentava sobre as partes importantes do texto e que não estavam, necessariamente, explícitas na obra.

Após a leitura mediada, os alunos deveriam elaborar um texto-resumo acerca do que havia sido tratado na obra e discutido em sala de aula, sendo que tal produção textual não deveria conter cópias do texto em análise. Com os resultados das produções textuais, analisamos qual foi o nível de interação que os estudantes fizeram com o texto lido, por meio de critérios preestabelecidos.

A partir dos resultados que obtivemos com o teste-piloto, fizemos algumas alterações para a elaboração das sequências didáticas com dois textos da apostila do projeto Água em Foco. O primeiro texto selecionado (texto 1) foi "O pH como parâmetro físico-químico da água e sua influência em ambientes aquáticos" (MORTIMER; COUTINHO; SILVA, 2012, p. 32-33). O segundo texto escolhido (texto 2) foi "Parâmetro físico-químico da água: Condutividade elétrica” (MORTIMER; COUTINHO; SILVA, 2012, p. 56-57).

A mediação de leitura desses textos foi trabalhada com oito turmas do terceiro ano do Ensino Médio, sendo quatro turmas para cada texto, em duas aulas não geminadas de cinquenta minutos cada.

Os dois textos tinham propostas de atividades diferenciadas. As atividades do texto 1 se dividiram em duas partes. A primeira delas objetivou levantar dados a respeito da opinião dos alunos sobre a obra e as possíveis dúvidas relacionadas à interpretação. A segunda parte teve como finalidade relacionar uma atividade de interpretação de rótulos de água mineral com as informações presentes nos rótulos e no texto analisado. Com a leitura desse texto e a realização das atividades propostas, pretendíamos trabalhar a habilidade H10, contida no Campo de Ciências da Natureza e suas Tecnologias, e o eixo cognitivo SP, os quais estão presentes na Matriz de Referência do Enem (INEP, 2012).

A atividade do texto 2 consistiu na produção de um texto-resumo pelos estudantes, objetivando saber a interação que eles fizeram com o texto, bem como auxiliá-los no desenvolvimento da habilidade H17, contida no Campo de Ciências da Natureza e suas Tecnologias, e o eixo cognitivo DL, ambos presentes na Matriz de Referência do Enem (INEP, 2012). 
A partir das respostas dos alunos, elaboramos critérios para análise das atividades, os quais serão apresentados na parte de resultados deste artigo. Tais critérios emergiram da análise das respostas dos estudantes às atividades propostas. Percebemos, com a leitura das respostas às atividades, um padrão, o qual nos possibilitou categorizá-las. Para o questionário, escolhemos para análise as respostas a duas questões: "Em que circusntâncias leem coisas de química" e "Dificuldades ao lerem coisas de química". Essa escolha ocorreu diante da intenção dos autores em identificar o tipo de leitura que mais atrairia esse grupo de estudantes e quais as dificuldades eles teriam nessas leituras relacionadas à disciplina de química. Para essas respostas, elaboramos 7 (sete) categorias de análise para a primeria questão (Gráfico 1), e 6 (seis), para a segunda questão (Gráfico 2).

As atividades de elaboração de questões sobre o texto lido (texto 1) foram baseadas em Francisco Júnior e Garcia Júnior (2010) e no livro Construindo Consciências (APEC, 2009). Nenhuma dessas atividades estava descrita na apostila do projeto Água em Foco como exercícios a serem feitos após a leitura do texto. Sentimos a necessidade de categorizar as respostas elaboradas pelos alunos; por isso, fundamentamo-nos em Paula e Lima (2010) para a análise das questões. Esses autores abordam o tema "Formulação de Questões e Mediação de Leitura" e indicam critérios de análise das questões elaboradas de forma que tais critérios retratem a forma com que os estudantes interagiram com o texto. Em nosso caso, observamos quatro categorias emergentes, que foram: "Dúvidas geradas durante a leitura"; "Perguntas em que a resposta está explícita no texto"; "Não elaboraram a questão"; "Dúvidas que extrapolam a leitura do texto" (Tabela 1).

Uma terceira atividade, que consistiu em analisar dois rótulos de água mineral sem gás e de marcas diferentes e o estabelecimento de relações entre as informações presentes nos rótulos e o texto lido (APEC, 2009), apresentou aos estudantes quatro questões elaboradas pelo professor mediador, para as quais os estudantes apresentaram respostas, que foram categorizadas de acordo com padrões emergentes. Assim, tivemos, para a primeira questão (Tabela 2), uma análise sobre a diferença das composições químicas dos rótulos; para a segunda questão, uma busca pelo valor de $\mathrm{pH}$; para a terceira questão, uma análise das quantidades expressas das substâncias presentes, e, para a quarta questão, uma explicação para as diferenças entres os valores de $\mathrm{pH}$ descritos.

Finalmente, para a quarta atividade, leitura mediada do texto 2 e produção de um texto-resumo a partir da leitura do texto em análise, baseamo-nos em Castello-Pereira (2003), que aborda o uso de estratégias variadas para a mediação de leitura de textos. Segundo esse autor, ensinar a estudar um texto inclui ensinar a sintetizar, a sistematizar, a ordenar as ideias, a reconstruir o dito e o não dito. Nesse caso, o resumo é uma estratégia que contribui para que o aluno possa organizar as ideias estudadas com suas próprias palavras. Para a análise dos resumos, utilizamos os mesmos critérios presentes na análise do teste-piloto, os quais totalizaram em 7 (sete), todos emergentes da leitura das produções dos estudantes. Os resultados da análise do teste-piloto foram comparados com os do texto 2 com o objetivo de verificar se houve avanços proporcionados pelas atividades de mediação de leitura, os quais podem ser identificados por meio de melhoria na presença das ideiaschave e coerência da apresentação dessas ideias. 


\section{RESULTADOS}

\section{Questionário realizado com os alunos}

O questionário foi realizado com 99 alunos, os quais participaram do projeto-piloto e, posteriormente, da mediação de leitura dos textos da apostila do projeto Água em Foco.

A resposta a uma das perguntas que compunha o questionário, com o objetivo de saber em que ocasiões os estudantes leem textos com conteúdos químicos, pode ser observada no Gráfico 1, a seguir:

GRÁFICO 1 - Em que circunstâncias os alunos leem textos relacionados à química

\section{Em que circunstâncias leem “coisas” de química}

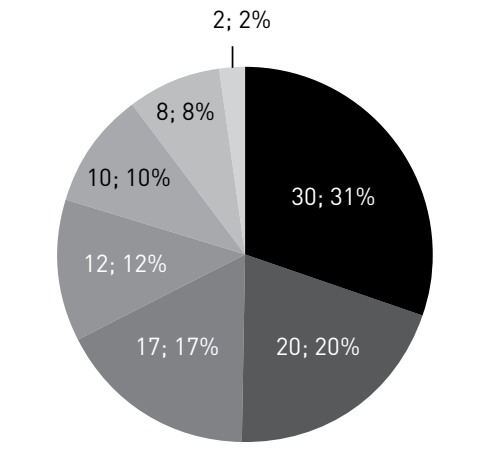

- Em aula

- Não entenderam ou não responderam

Véspera de avaliações

Nas aulas e em casa

Quando solicitado pelo professor

Para fixar a matéria

Não leem

Fonte: Elaboração pelos autores deste artigo.

Os dados acima podem demonstrar que poucos alunos acham relevante a leitura de conteúdos químicos fora do ambiente escolar. Isso pode ser observado pelo grande número de estudantes que somente leem "coisas de química" quando solicitado pelo professor, ou antes das atividades avaliativas, ou que relataram que não leem textos relacionados à química.

Não colocaremos aqui um ideal da frequência ou da habitualidade de os alunos lerem textos relacionados à química, mas entendemos que, se a leitura de "coisas de química" for feita apenas para a fixação da matéria, como uma forma mecânica de descobrir dados, dificilmente conseguiremos melhorar a habilidade dos estudantes para ler textos científicos didáticos.

A leitura mediada de textos relacionados à química pode auxiliar os estudantes no entendimento de assuntos associados ao seu cotidiano e que estão diretamente ligados aos conteúdos de química ensinados no ambiente escolar.

Dessa forma, é importante que o professor adote a leitura em sala de aula para que os alunos desenvolvam a habilidade de leitura e possam usá-la em 
ocasiões escolares e, também, em ocasiões que não sejam, necessariamente, dentro do contexto escolar.

Outra pergunta do questionário trata das dificuldades que os estudantes enfrentam ao ler textos específicos de química. As respostas a essa questão podem ser observadas no Gráfico 2.

GRÁFICO 2 - Dificuldades que os alunos enfrentam ao ler textos relacionados à química

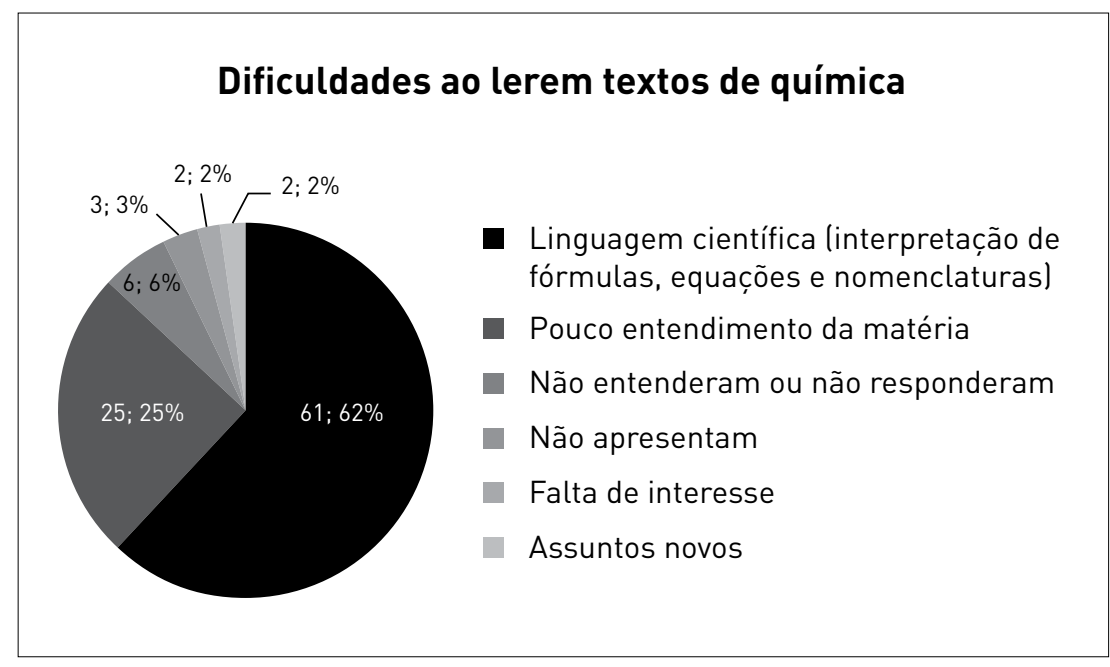

Fonte: Elaboração pelos autores deste artigo.

Embora o questionário tenha sido realizado com alunos do terceiro ano, não podemos desprezar o fato de que a química apresenta uma linguagem nova para alunos de Ensino Médio. Tanto em fórmulas como em novas palavras ou, até mesmo, em palavras que já eram de conhecimento dos alunos no cotidiano, mas que apresentam significados completamente diferentes na linguagem científica, como: calor, temperatura, ligação, equilíbrio, afinidade, etc.

É certo que um texto pode ter inúmeras interpretações, pois o entendimento de quem o lê depende de vários fatores, como o contexto sociocultural do aluno, os objetivos da leitura, o momento histórico, etc. Entretanto, segundo Espinoza (2010), dizer que podemos interpretar um texto de várias maneiras não significa que qualquer interpretação seja válida. A dificuldade de entendimento dos novos conceitos pode levar os alunos a ter uma dificuldade de interpretação de textos científicos, caso não haja um professor mediador no momento da leitura. Dessa forma, é importante que o professor tente romper com as barreiras tradicionais de mediação de leitura em sala de aula, para que ele consiga perceber as dificuldades envolvidas na interpretação dos estudantes.

\section{Resultados da mediação de leitura dos textos da apostila do projeto Água em Foco}

Após a interpretação das obras, os alunos fizeram atividades, que apresentavam encaminhamentos diferentes. Como a proposta foi realizada em duas 
aulas não geminadas, selecionamos para análise apenas as atividades dos alunos que participaram das duas aulas. Ao total, foram 116 (cento e dezesseis) atividades analisadas, sendo 54 (cinquenta e quatro) do texto 1, e 62 (sessenta e duas), do texto 2.

\section{Análise texto 1}

Embora os textos da apostila Água em Foco: Qualidade de Vida e Cidadania (MORTIMER; COUTINHO; SILVA, 2012) sejam densos no que diz respeito a conteúdos científicos, a maioria dos alunos considerou a leitura do texto como sendo razoavelmente fácil ou fácil e a compreensão foi considerada pela maioria desses estudantes como razoável ou boa.

Com o objetivo de analisar a interação dos estudantes com o texto lido, pedimos para que os alunos realizassem uma atividade que consistia na elaboração de questões as quais eles gostariam que fossem discutidas e debatidas em sala de aula. Nessa atividade, baseada na proposta de Francisco Júnior e Garcia Júnior (2010), os alunos deveriam formular questões nas quais tiveram dúvidas, que não foram sanadas com a mediação da leitura, ou, ainda, questões em que a resposta não estava explícita na obra e que eles gostariam que o professor discutisse.

Representaremos algumas respostas elaboradas pelos alunos, que foram identificados pela turma (três primeiros números), seguido da letra A (aluno) e seu número na lista de chamada. Dessa forma, o educando identificado como 214A22 pertence à turma 214 e é o aluno cujo número de chamada é o 22.

$\mathrm{Na}$ análise da atividade descrita, dividimos as perguntas em categorias de A a D. Essas categorias foram baseadas no artigo de Paula e Lima (2010, 2011) e podem ser observadas na Tabela 1 , juntamente com a quantidade de alunos que elaboraram as respectivas questões.

TABELA 1 - Questões elaboradas pelos estudantes para posterior discussão com o professor

\begin{tabular}{|l|c|}
\hline Elaborar questões que gostaria que fossem discutidas em sala de aula & No de alunos \\
\hline A) Dúvidas geradas durante a leitura & 24 \\
\hline B) Perguntas em que a resposta está explícita no texto & 25 \\
\hline C) Não elaboraram a questão & 3 \\
\hline D) Dúvidas que extrapolam a leitura do texto & 2 \\
\hline
\end{tabular}

Fonte: Elaboração pelos autores deste artigo.

A maioria dos alunos elaborou questões em que a resposta já estava explícita no texto. Podemos entender que alguns dos 25 estudantes que elaboraram questões de discussão do tipo B tiveram dificuldades com a interpretação do texto lido, o que pode ter contribuído para que eles elaborassem questões de discussão em que as respostas estavam explícitas na obra.

Entretanto, com os 24 (vinte e quatro) estudantes que elaboraram 
questões do tipo A, "ficam mais evidentes as dúvidas geradas durante a leitura e os problemas conceituais que eles carreiam da Educação Escolar” (FRANCISCO JÚNIOR; GARCIA JÚNIOR, 2010, p. 198).

Como funcionam as estações de tratamento de água? (216A14)

Acho que não ficou muito claro o que épH para mim, então gostaria de saber com exemplo o que é. (215A04)

Um dos fatores que contribui para o decréscimo no valor do $p H$, ou mesmo influenciar o seu indice médio, são as construções de hidrelétricas. Em relação ao que se aborda, qual a intervenção mais apropriada para o uso contínuo das hidrelétricas sem danificar ou alterar o ciclo e o indice proporcional do $p H$ nos ambientes aquáticos? (214A12)

Qual a importância do pH para a vida bumana? (213 A16)

Referimo-nos às questões que extrapolam a leitura do texto (tipo D), como as dúvidas que os alunos tiveram durante a leitura, nas quais os temas das perguntas eram abordados indiretamente na obra. Isso nos indica uma interação bastante efetiva por parte desses leitores, pois eles conseguiram interagir com o texto de forma a refletir sobre as entrelinhas escritas pelo autor. A seguir, listamos as duas questões que consideramos como do tipo D: Por que as algas vivas não influenciam na cor do rio e as mortas sim? (216A25) e Por que há liberação de CH4 onde se constroem as hidrelétricas? (216A19).

Percebemos, com a análise das questões dos estudantes, que, para alguns deles, pode não ter havido um aprendizado efetivo acerca do tema, uma vez que não ficou claro o conceito de $\mathrm{pH}$, essencial para uma maior interação com o que foi lido. Entretanto, notamos que, para outros estudantes, a interação com o texto foi de tal forma que os incentivou a querer saber mais sobre o tema, o que pode ser observado para os comentários dos alunos 214A12, 216A14, 2016A25 e 2016A19. É importante que o professor mediador discuta com os alunos as questões alvos de dúvidas, pois, dessa forma, há a possibilidade de um aprendizado mais efetivo por parte dos estudantes. Entendemos a mediação da leitura em sala de aula como a constituição de uma prática social dialógica (mediada pela palavra) e pedagógica (mediada pelo outro).

O professor estimula os estudantes, busca suas contrapalavras nesse processo de leitura. Como nos diz Geraldi $(2007)^{7}$, citado por Silveira Júnior, Lima e Machado (2015a, p. 647), um leitor/ouvinte que não oferece às palavras lidas/ouvidas as suas contrapalavras recusa a experiência da leitura. É preciso vir carregado de palavras para o diálogo com o texto. Mais simples, talvez, seria a explicação direta sendo dada pelo professor. Mas, conforme nos mostra Bakhtin (2003), para a compreensão, necessitamos de mais de uma consciência. $\mathrm{Na}$ explicação, existe apenas uma consciência, um sujeito.

A mediação da leitura do texto na sala de aula ultrapassa a dimensão da mera exposição/explicação do professor porque introduz um terceiro ponto de vista, com o qual é preciso lidar. O professor já iniciado nos discursos e nas práticas da ciência é o par mais capaz, do qual fala Vigotski (2008), para negociar sentidos e 
circunscrevê-los aos domínios de validade dos mesmos. Sendo o encontro de, pelo menos, três sujeitos - autor, professor e estudantes -, o texto didático é, talvez, a forma mais rica de ensinar e aprender na sala de aula.

Após a elaboração das questões e o entendimento das dúvidas dos alunos, suas opiniões a respeito do texto lido e a interação que eles fizeram com a obra, era o momento de auxiliá-los no desenvolvimento da competência de enfrentamento de situações-problema (SP) (INEP, 2012).

Pensando nisso, pedimos para que os alunos respondessem à questão que consistia em analisar dois rótulos de água mineral sem gás e de marcas diferentes para que eles pudessem fazer correlações entre as informações presentes nos rótulos e o texto lido. Entendemos que essa questão os coloca frente a uma situação-problema, pois os estudantes devem tentar entender por que as informações das composições químicas e o pH dos rótulos são diferentes. As questões propostas para a atividade (APEC, 2009) e os dados resultantes das respostas dos estudantes são apresentados na Tabela 2.

TABELA 2 - Resultado da questão de análise de rótulos de água mineral

\begin{tabular}{|c|c|c|c|}
\hline Questão(A) & $\begin{array}{l}\text { No de } \\
\text { alunos }\end{array}$ & Questão (C) & $\begin{array}{l}\mathrm{N}^{\circ} \text { de } \\
\text { alunos }\end{array}$ \\
\hline \multicolumn{2}{|c|}{$\begin{array}{l}\text { As composições químicas descritas nos } \\
\text { rótulos das águas são as mesmas? }\end{array}$} & \multicolumn{2}{|l|}{ Qual é o valor do $\mathrm{pH}$ de cada rótulo? } \\
\hline Não & 45 & Coerente com o rótulo & 47 \\
\hline $\operatorname{Sim}$ & 7 & Incoerente com o rótulo & 4 \\
\hline Não Responderam & 2 & Não responderam & 3 \\
\hline Questão (B) & $\begin{array}{l}\text { No de } \\
\text { alunos }\end{array}$ & Questão (D) & $\begin{array}{l}N^{\circ} \text { de } \\
\text { alunos }\end{array}$ \\
\hline \multicolumn{2}{|c|}{$\begin{array}{c}\text { As substâncias que aparecem em ambos } \\
\text { os rótulos se apresentam na mesma } \\
\text { quantidade? Por que isso acontece? }\end{array}$} & \multicolumn{2}{|c|}{$\begin{array}{c}\text { De acordo com o texto e, com base nas } \\
\text { informações fornecidas pelos rótulos, explique } \\
\text { esta diferença de } \mathrm{pH} \text {. }\end{array}$} \\
\hline $\begin{array}{l}\text { Relacionaram as composições } \\
\text { químicas dos rótulos com fontes } \\
\text { de água ou locais diferentes }\end{array}$ & 20 & $\begin{array}{l}\text { Relacionaram os valores diferentes } \\
\text { de } \mathrm{pH} \text { com as diferentes composições } \\
\text { químicas ou a quantidade delas }\end{array}$ & 13 \\
\hline $\begin{array}{l}\text { Não relacionaram as } \\
\text { composições dos rótulos com as } \\
\text { fontes e nem com o texto }\end{array}$ & 15 & $\begin{array}{l}\text { Relacionaram os valores diferentes } \\
\text { de } \mathrm{pH} \text { com a maior ou menor } \\
\text { presença de bicarbonatos descrita } \\
\text { nos rótulos }\end{array}$ & 8 \\
\hline $\begin{array}{l}\text { Relacionaram as composições } \\
\text { com o texto, mas a resposta não } \\
\text { foi satisfatória. }\end{array}$ & 1 & $\begin{array}{l}\text { Não relacionaram os valores } \\
\text { diferentes de } \mathrm{pH} \text { com o texto ou com } \\
\text { o rótulo }\end{array}$ & 5 \\
\hline Não Justificaram & 13 & $\begin{array}{l}\text { Relacionaram os valores diferentes } \\
\text { de pH com solos diferentes e outras } \\
\text { informações presentes no texto }\end{array}$ & 1 \\
\hline \multirow[t]{2}{*}{ Não Responderam } & 5 & Não responderam & 17 \\
\hline & & $\begin{array}{l}\text { Relacionaram o pH com o texto, mas } \\
\text { a resposta não foi satisfatória }\end{array}$ & 10 \\
\hline
\end{tabular}

Fonte: Elaboração pelos autores deste artigo. 
As questões (A) e (C) são apenas de observação dos rótulos em análise e, por isso, esperávamos que um maior número de alunos conseguisse fazer a associação corretamente. O objetivo delas na atividade era direcionar os estudantes para as questões (B) e (D), respectivamente.

As questões (B) e (D) demandavam maior interpretação dos alunos com os rótulos e também com o texto 1 analisado anteriormente. Dessa forma, para que essas questões fossem respondidas adequadamente, era necessário que o nível de interação do aluno com o texto tivesse sido satisfatório.

A questão (B) solicitava aos alunos que respondessem se as substâncias que aparecem em ambos os rótulos se apresentam na mesma quantidade e o porquê das possíveis diferenças. Com a análise dos rótulos, percebemos que as substâncias presentes em ambos estão em quantidades diferentes. Isso porque elas são provenientes de fontes diferentes e, com a interpretação do texto, os alunos deveriam ser capazes de entender que solos de regiões diferentes possuem, também, diferentes composições químicas, onde as substâncias estão presentes em maior ou menor quantidade.

Obtivemos 20 (vinte) respostas satisfatórias para a questão (B). Todas elas relacionaram as composições químicas dos rótulos com fontes de água ou locais diferentes. Apresentamos a seguir alguns exemplos dessas respostas:

Não. Pois a água dos dois rótulos é retirada de locais diferentes, o que quer dizer que cada local tem um valor de minerais diferente. (216A34)

Não, isso porque as águas vieram de fontes diferentes, que foram infuenciadas por situações diferentes. Além disso, a água foi tratada de maneiras diferentes por empresas diferentes. (215A08)

Não. Já que são de fontes diferentes mudam suas composições. (213A28)

Entretanto, a maioria dos alunos (34) teve dificuldades em responder a essa questão.

Porque as substâncias não apresentam a mesma quantidade por conta da composição quimica. (216 A08)

Não. Uma garrafa tem mais água do que a outra. (215A12)

Não se apresentam na mesma quantidade, pois o pH delas na mesma temperatura varia. (215 A24)

Não. Porque determinadas condições de pH contribuem para a precipitação de elementos químicos tóxicos como metais pesados. (213A16)

Entendemos que a relação entre o texto e os rótulos, para esses estudantes, foi difícil. Isso pode se encaixar na dificuldade de interpretação de dados científicos que esses alunos enfrentam. A continuada prática de leitura e interpretação de questões como essa pode auxiliar os alunos no desenvolvimento dessa competência.

Obtivemos resultados parecidos para a questão (D), que solicitava que os alunos explicassem a diferença de $\mathrm{pH}$ dos rótulos de acordo com o texto e 
com base nas informações fornecidas pelos rótulos. Esperávamos que os alunos explicassem que a diferença no $\mathrm{pH}$ das águas é devido às distintas composições dos produtos e às suas quantidades especificadas, pois o $\mathrm{pH}$ do meio será influenciado pela maior ou a menor quantidade de substâncias dissolvidas.

Apenas 21 (vinte e um) alunos responderam satisfatoriamente a essa questão. Treze (13) estudantes relacionaram os valores diferentes de $\mathrm{pH}$ com as diferentes composições químicas ou a quantidade delas. Outros 8 (oito) estudantes relacionaram os valores diferentes de $\mathrm{pH}$ com a maior ou a menor presença de bicarbonatos descrita nos rótulos.

As substâncias das águas, suas quantidades, a época em que foram coletadas, o local da fonte, o modo no qual foram tratadas por cada empresa, são exemplos da causa da diferença de $p H$. (216 A10)

Essa diferença está relacionada à quantidade de cada substância. (214A23)

No rótulo $B$ por possuir mais bicarbonato o $p H$ é maior e no rótulo A que tem menos, o $p H$ é menor. (216A14)

$O \mathrm{pH}$ do rótulo $\mathrm{B}$ é maior, pois a quantidade de bicarbonato presente é muito maior. (214 A01)

Entretanto, 33 (trinta e três) estudantes não conseguiram compreender corretamente o porquê das diferenças de $\mathrm{pH}$ dos rótulos e confundiram o objetivo da questão (D) com a questão (B).

A diferença de $\mathrm{pH}$ depende da localização das fontes retiradas da água, pois depende da região e da fauna e flora ao redor. (213A25)

Porque são águas distintas com características quimicas diferentes. (215 A06)

A diferença de pH está relacionada com o meio e seu estado de decomposição orgânica, etc. (215 A22)

Uma característica central da mediação pedagógica proposta consistia, como proposto por Silveira Júnior, Lima e Machado (2015a), em buscar no texto, com os estudantes, pistas, marcas ou indícios de relacionamento com as ideias centrais em discussão (GINZBURG, 1989). A intenção era avançar sempre mais no sentido de dar determinado acabamento às questões tratadas pelos textos e os variados sentidos que vieram sendo atribuídos/negociados na aula. O que significa, portanto, que o acabamento não estava relacionado ao fechamento de sentidos, mas à inscrição destes em marcos conceituais mais amplos pela recursividade.

Portanto, compreendemos que o eixo cognitivo de enfrentamento de situação-problema (SP) (INEP, 2012) deve ser continuamente trabalhado, pois, apesar de entendermos que essa mediação de leitura e atividade pode ter contribuído para auxiliar os alunos no desenvolvimento dessa competência, muitos desses estudantes ainda não conseguiram desenvolvê-la satisfatoriamente. 


\title{
Análise da atividade do texto 2
}

A atividade do texto 2, que consistiu na produção de um texto-resumo a partir da leitura do texto em análise, já havia sido realizada anteriormente no teste-piloto. Essa atividade tinha como objetivos principais o desenvolvimento da habilidade 17 (INEP, 2012) e o aperfeiçoamento do eixo cognitivo de domínio de linguagens (DL).

No sentido dito por Castello-Pereira (2003), a compreensão de um texto passa também pela produção textual pelos estudantes.

\begin{abstract}
Ensinar a estudar um texto é ensinar a utilizar as estratégias cognitivas necessárias para questionar o texto e acionar os conhecimentos prévios; é ensinar a localizar os indícios deixados no texto e coletá-los como informações para construir o sentido do texto; é ensinar a realizar inferências, a investigar o pensamento do autor, a fazer triagem das informações, a sintetizar, a sistematizar, a ordenar as ideias, a reconstruir o dito e o não dito. O estudo e a reflexão supõem, entre outros, o uso de recursos como sublinhar, anotações de margem de texto, marcas diversas que orientem a leitura, fichamento, resumo, esquema. Esses recursos possibilitam compreender o texto, investigar e ordenar as ideias do autor, enfim, possibilitam realizar o estudo do texto. Todos esses recursos e estratégias devem ser ensinados pelo professor através de mediação constante (CASTELLO-PEREIRA, 2003, p. 78).
\end{abstract}

O comando da questão pedia que os alunos fizessem o texto-resumo individualmente e sem cópias do texto em análise. O professor escolheu oito palavras-chave para guiar o entendimento do texto (o que não havia acontecido na atividade do teste-piloto), as quais deveriam ser abordadas pelos alunos em suas produções. Acreditamos que, quando os alunos procuram reorganizar suas ideias para escrever um resumo com suas próprias palavras, eles precisam relacionar o seu pensamento sobre tudo o que foi aprendido com as informações contidas nos textos. Entendemos que essa prática, além de auxiliar os alunos na produção dos textos, ainda contribui para o desenvolvimento da habilidade 17 (INEP, 2012).

Analisamos as produções escritas dos estudantes em busca dos indícios do desenvolvimento do processo de compreensão, bem como estivemos atentos aos sentidos produzidos com as leituras, de forma a recuperar a caminhada interpretativa desses estudantes, de forma análoga ao processo descrito por Silveira Júnior (2012, p. 80):

\footnotetext{
Desse modo, nossa escolha pela análise das produções escritas dos estudantes nos coloca como participantes desse diálogo de forma diferente do que seria se optássemos pela análise da interação oral. A partir de momentos congelados, vamos buscar os indícios do movimento. Fontana (1996) ${ }^{8}$, citando Vigotski (2001), diz a nós que o registro escrito, em sua especificidade, exige um processo de elaboração, uma atividade mental distinta daquela propiciada pela interação oral. A escrita tem que ser conscientemente dirigida. Seus motivos não vão sendo, como na interlocução oral, explicitados e determinados pela própria situação dinâmica da interlocução. Ela exige ação analítica deliberada e, para que se torne inteligível, a teia do significado tem que ser estruturada intencionalmente, isto é, tem que ser detalhada e procurar explicar plenamente a situação.
} 
Espinoza (2006) defende que a realização de experimentos e de atividades de escrita pelos estudantes serve à problematização dos conteúdos. Assim, a utilização da leitura deve ocorrer no âmbito de uma série de situações das quais os estudantes precisam tomar parte: observações, experimentação, resolução de problemas, produção de textos (ESPINOZA, 2010).

Os resultados obtidos com as novas produções encontram-se no Gráfico 3. A análise desses dados baseou-se na comparação dos resultados obtidos com os resumos da atividade do teste-piloto. Para isso, utilizamos os mesmos critérios de análise na avaliação dos resumos do texto 2 .

GRÁFICO 3 - Produção textual dos alunos com base no texto 2

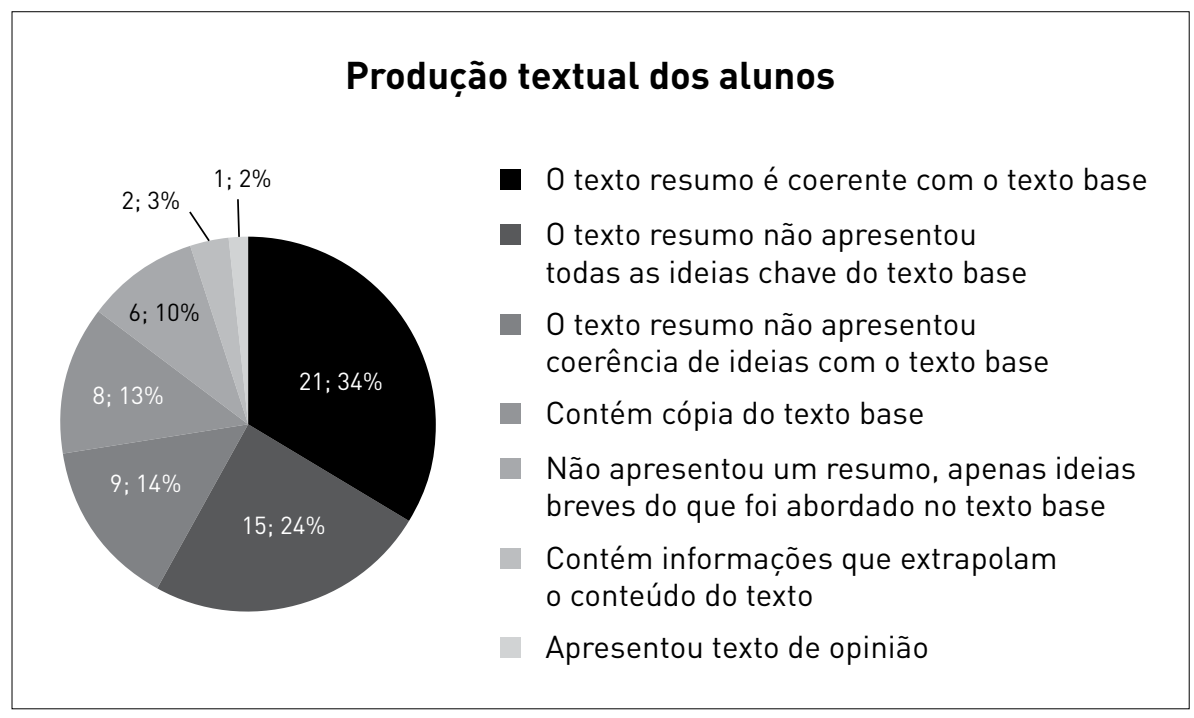

Fonte: Elaboração pelos autores deste artigo.

Nas análises, como no trabalho de Silveira Júnior (2012), buscamos os indícios do desenvolvimento do processo de compreensão por parte dos estudantes. Para Amorim (2001), toda interpretação ou compreensão, termos utilizados por Bakhtin como equivalentes, consiste em opor um enunciado a outro. O sentido é o produto da relação complexa que se tece entre o texto, objeto de estudo e de reflexão, e o contexto discursivo que o transmite e no qual se realiza o pensamento cognoscente. Aquele que faz ato de compreensão de um texto torna-se ele próprio participante do diálogo.

Devemos fazer observações antes de confrontarmos os resultados. Para a análise dos dados, foram consideradas como "textos resumos que não apresentaram todas as ideias-chave do texto-base" aquelas produções que continham menos de cinco palavras-chave especificadas no comando da questão ou para as produções que não relacionaram a concentração dos íons como um parâmetro passível de determinação da qualidade da água (ou causa de impactos ambientais). Além disso, consideramos como produções que "continham 
informações que extrapolavam o conteúdo do texto" as produções que eram cópias de textos retirados da internet.

Comparando as produções textuais do teste-piloto e do texto 2, podemos observar uma evolução dos resultados. Para visualizarmos essa comparação, fizemos um novo gráfico (Gráfico 4), o qual apresenta as porcentagens de alunos juntamente com o critério de análise em que suas produções textuais foram encaixadas.

GRÁFICO 4 - Comparação entre os resultados dos resumos do teste-piloto e do texto 2

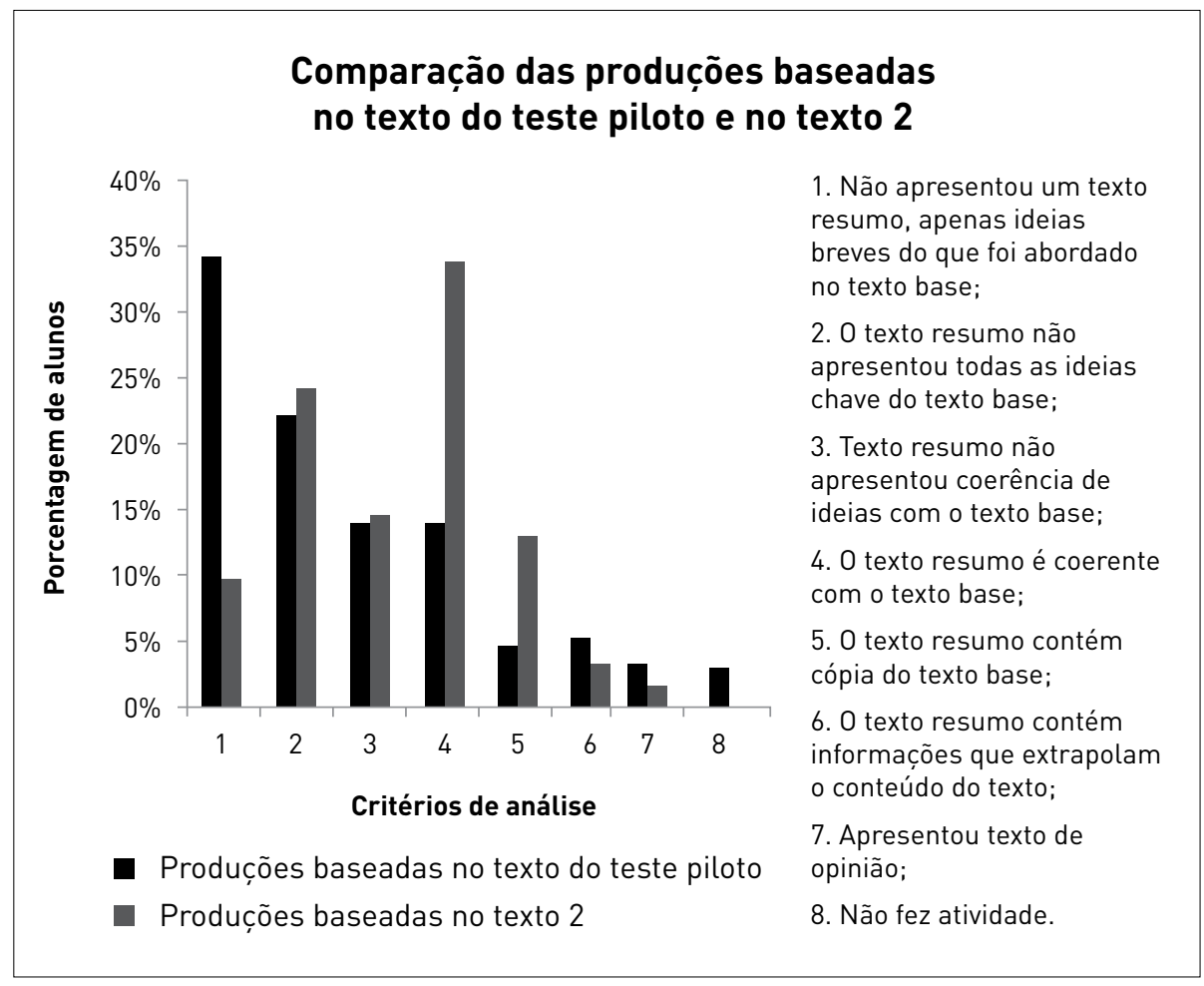

Fonte: Elaboração pelos autores deste artigo.

Os dados utilizados para a análise do teste-piloto nos mostram que apenas $14 \%$ dos estudantes fizeram textos coerentes com o texto-base. Esse índice subiu para 34\% com a nova produção textual dos estudantes. Vale ressaltar neste ponto que, após o teste-piloto, a professora das turmas começou a trabalhar com mais frequência a leitura de textos científicos escolares com os alunos. Essa prática pode ter contribuído para a evolução dos educandos na habilidade de domínio de linguagem científica, desenvolvendo, além da compreensão de textos científicos, a capacidade de escrita sobre o tema abordado.

Com o aumento das produções textuais coerentes com as ideias dos textosbase, tivemos uma diminuição significativa dos alunos que apresentaram apenas 
ideias breves do que havia sido abordado no texto em análise. Consideramos que esse resultado se deve, também, ao melhoramento no comando da questão, em que os alunos deveriam abordar as palavras-chave indicadas pelo professor mediador.

Entretanto, com a descrição das palavras-chave, obtivemos um maior índice de alunos que fizeram produções com cópias do texto-base em relação às produções do teste-piloto. Entendemos que isso se deve ao fato de esses estudantes ainda apresentarem dificuldades de se expressar por meio da escrita, ou porque esses educandos não conseguiram fazer uma interação satisfatória com o texto ou com o tema, mesmo após a mediação de leitura. Segundo Espinoza (2010, p. 158),

\footnotetext{
Para escrever um texto, é preciso haver uma interação permanente entre uma representação interna do sujeito e a correspondência externa que vai sendo produzida. Quando falamos "sujeito", pensamos naquilo que o aluno sabe a respeito de um tema específico sobre o qual escreve, no motivo pelo qual escreve e na imagem dos potenciais interlocutores que lerão o que está escrevendo.
}

Observamos que as demais categorias permaneceram relativamente constantes de uma produção textual para a outra. Entendemos que a constante prática de leitura, discussão e resumo de textos científicos pode auxiliar os alunos no desenvolvimento não só do pensamento crítico, mas também das competências de domínio de linguagens (DL) e também na habilidade de relacionar informações apresentadas na forma de texto discursivo (H17).

Ressalvamos, aqui, que os estudantes que fizeram produções textuais não satisfatórias com o que era proposto pelo comando da questão podem ter encontrado dificuldades na passagem da linguagem oral para a linguagem escrita. Para averiguar a veracidade dessa proposição, seria necessário realizar uma entrevista com os alunos que produziram os textos e verificar se o que eles escreveram é condizente com o que eles pensam a respeito do assunto abordado em sala de aula. Deixamos tal aspecto indicado para futuras pesquisas a respeito do tema Leitura e Escrita no ensino de ciências.

\section{CONSIDERACְ̃̃ES FINAIS}

Trabalhar com a leitura no ensino de ciências nos ajudou a entender que a mediação de leitura pode ajudar os alunos a construir ideias coerentes acerca da sua própria interpretação textual de textos científico-didáticos, pois, assim como afirmam Francisco Júnior e Garcia Júnior (2010), trabalhar em sala de aula textos de gênero científico-escolar contribui para a formação plena de cidadãos, pelo fato de propiciar aos estudantes um contato e interação com a Ciência. Nos apoiamos também em Espinoza (2010), quando indicamos que é importante ler textos de ciências para aprender ciências, e em Suisso e Galieta (2015), ao defenderem que, para diversos autores, saber ler e escrever a linguagem da Ciência é condição essencial para que o indivíduo seja considerado letrado científica e tecnologicamente.

Além disso, percebemos que a mediação de leitura de textos científicos escolares em sala de aula é importante no auxílio para o desenvolvimento das 
habilidades $\mathrm{H} 10$ e H17 pelos estudantes, bem como as atividades elaboradas a partir da interpretação das obras, que podem interferir no aperfeiçoamento das competências de domínio de linguagem (DL) e enfrentamento de situaçõesproblema (SP), presentes na Matriz de Referência do Enem (INEP, 2012).

Os dados deste trabalho se mostram positivos em relação à progressão dos alunos em trabalhar com textos do gênero científico-didático. Entendemos que esses resultados nos levam a perceber e confirmar a necessidade de abordarmos com mais frequência a leitura nas aulas de ciências e mudarmos os métodos de avaliação dos alunos com a leitura. Assim, poderíamos observar, como professores, quais são os tipos de dificuldades enfrentadas por nossos estudantes e, dessa forma, teríamos a possibilidade de mudar os dados apontados pela SAEB de 2003, entre outras avaliações, que mostram a criticidade do desenvolvimento de leitura de alunos do Ensino Médio.

Embora esse tipo de atividade demande do professor dedicação maior, consideramos que a atividade proposta foi bastante válida, visto que nos deu uma visão real da necessidade da implantação de estratégias que visem auxiliar os estudantes no desenvolvimento de habilidades tão importantes, não só no ambiente escolar, mas em qualquer ambiente que exija desses alunos maior criticidade em relação à interpretação.

Iniciamos apontando que o tema leitura no ensino de ciências é um assunto com poucas publicações em periódicos. Entretanto, entendemos que esse é um tema relevante para o desenvolvimento de habilidades essenciais para alunos de Ensino Médio. Dessa forma, deixamos indicado aqui que existem possibilidades de novas pesquisas sobre o tema, como a elaboração de novas atividades que promovam o desenvolvimento das habilidades de leitura e escrita de textos contendo "coisas de química" no contexto do planejamento habitual do professor.

\section{NOTAS}

${ }^{1}$ Utilizamos como referência os Parâmetros Curriculares Nacionais de 2009, pois, até a conclusão deste artigo, a Base Nacional Comum Curricular estava em processo de elaboração.

${ }^{2}$ GERALDI, J. W. (Org.). O texto na sala de aula. Cascável: Assoeste, 1984.

${ }^{3}$ LARROSA, J. Experiência e alteridade em educação. Reflexão e Ação, Santa Cruz do Sul, v. 19, n. 2, p. 4-27, 2011.

${ }^{4}$ BRANDÃO, H. H. N. Escrita, leitura, dialogicidade. In: BRAIT, B. (Org.). Bakhtin: dialogismo e construção do sentido. 2. ed. Campinas: Editora da Unicamp, 2005. p. 265-273.

${ }^{5}$ GERALDI, J. W.; FICHTNER, B.; BENITES, M. Transgressões convergentes: Vigotski, Bakhtin, Bateson. Campinas: Mercado de Letras, 2006. 200 p. 
${ }^{6}$ FREITAS, M. T. A. Discutindo sentidos da palavra intervenção na pesquisa de abordagem histórico-cultural. In: FREITAS, M. T. A.; RAMOS, B. S. (Org.). Fazer pesquisa na abordagem históricocultural: metodologias em construção. Juiz de Fora: Ed. da UFJF, 2010. p. 13-24.

${ }^{7}$ GERALDI, J. W. Leitura: uma oferta de contrapalavras. In: GEGe - Grupo de Estudos dos Gêneros do Discurso. O espelho de Bakhtin. Campinas: Pedro \& João Editores, 2007.

${ }^{8}$ FONTANA, R. A. C. Mediação pedagógica na sala de aula. Campinas: Autores Associados, 1996. 176 p.

\section{REFERÊNCIAS}

AMORIM, M. O pesquisador e seu outro: Bakhtin nas ciências humanas. São Paulo: Musa, 2001. 304 p. APEC - AÇÃO E PESQUISA EM EDUCAÇÃO EM CIÊNCIAS. Construindo Consciências: Ciências $-6^{\circ}$ ano. Ensino Fundamental. 3. ed. São Paulo: Scipione, 2009. 280 p.

BAKHTIN, M. Estética da criação verbal. 4. ed. São Paulo: Martins Fontes, 2003.

BAKHTIN, M. Estética da criação verbal. 6. ed. São Paulo: Martins Fontes, 2010.

BAKHTIN, M. Marxismo e filosofia da linguagem. 12. ed. São Paulo: Hucitec, 2006.

BRASIL. Ministério da Educação. Parâmetros curriculares nacionais para o

Ensino Médio: orientações educacionais complementares aos PCN. Brasília: MEC, 2009.141 p. Disponível em: <http://portal.mec.gov.br/seb/arquivos/pdf/ CienciasNatureza.pdf > . Acesso em: 07 mar. 2014.

CANTO, E. L. do; PERUZZO, T. M. Química: na abordagem do cotidiano. 4. ed. São Paulo: Moderna, 2006. v. 3, 264 p.

CASTELLO-PEREIRA, L. T. Leitura de Estudo: ler para aprender a estudar e estudar para aprender a ler. Campinas: Alínea, 2003.

ESPINOZA, A. La especificidad de las situaciones de lectura em "naturales". Lectura y vida: Revista Latinoamericana de Lectura, Buenos Aires, v. 27, n. 1, p. 6-16, 2006.

ESPINOZA, A. Ciências na escola: novas perspectivas para a formação dos alunos. Tradução de Camila Bogea. São Paulo: Ática, 2010.

FLÔR, C. C. Leitura e formação de leitores em aulas de química no Ensino Médio. 2009. 235 f. Tese (Doutorado em Educação Científica e Tecnológica) - Centro de Ciências da Educação, Universidade Federal de Santa Catarina, Florinópolis, 2009. Disponível em: <https://repositorio.ufsc.br/bitstream/handle/ 123456789/92247/275216.pdf?sequence=1 >. Acesso em: 24 out. 2014.

FRANCISCO JÚNIOR, W. E. F. Estratégias de leitura e educação química: que relações? Química Nova na Escola, São Paulo, v. 32, n. 4, p. 220-226, 2010. Disponível em: < http:/ qnesc.sbq.org.br/ online/qnesc32_4/03-EA5809.pdf>. Acesso em: 19 out. 2016.

FRANCISCO JÚNIOR, W. E.; GARCIA JÚNIOR, O. Leitura em sala de aula: um caso envolvendo o funcionamento de ciência. Química Nova na Escola, São Paulo, v. 32, n. 3, p. 191-199, 2010. Disponível em: <http://qnesc.sbq.org.br/online/qnesc32_3/ 09-PE-8809_novo.pdf>. Acesso em: 19 out. 2016 
GERALDI, J. W. A aula como acontecimento. São Carlos: Pedro \& João Editores, 2010.

GINZBURG, C. Mitos, emblemas, sinais: morfologia e história. São Paulo: Companhia das Letras, 1989. $281 \mathrm{p}$.

INEP - INSTITUTO NACIONAL DE ESTUDOS E PESQUISAS ANÍSIO TEIXEIRA (Brasil). Matriz de referência Enem. Brasília, 2012. 79 p. Disponível em: <http://download.inep.gov.br/educacao_basica/enem/downloads/2012/ matriz_referencia_enem.pdf $>$. Acesso em: 24 out. 2014.

MORTIMER, E. F.; COUTINHO, F.; SILVA, P. S. Projeto água em foco: qualidade de vida e cidadania. Belo Horizonte, 2012. 86 p.

PAULA, H. F.; LIMA, M. E. C. C. A leitura de textos didáticos de ciências como confronto de perspectivas. Ensaio: Pesquisa em Educação em Ciências, Belo Horizonte: FaE/UFMG: CECIMIG, v. 13, n. 3, 2011. Disponível em: < http://www.scielo.br/pdf/epec/v13n3/1983-2117epec-13-03-00185.pdf>. Acesso em: 25 out. 2016.

PAULA, H. F.; LIMA, M. E. C. C. Formulação de questões e mediação da leitura. Investigações em ensino de ciências, Porto Alegre, v. 15, n. 3, p. 429-461, 2010. Disponível em: <https://www. if.ufrgs.br/cref/ojs/index.php/ienci/article/view/257 >. Acesso em: 25 out. 2016.

QUADROS, A. L.; SILVA, D. C.; SILVA, F. C. Formulação de questões a partir da leitura de um texto: desempenho dos estudantes de licenciatura em Química da modalidade à distância. Revista Ensaio, Belo Horizonte: FaE/UFMG: CECIMIG, v. 13, n. 1, p. 43-56, jan./abr. 2011. Disponível em: < http://www.portal.fae.ufmg. br/seer/index.php/ensaio/article/view/376>. Acesso em: 25 out. 2016.

SANTOS, W. L. P.; SCHNETZLER, R. P. Função social: o que significa ensino de química para formar o cidadão. Química Nova na Escola, São Paulo, n. 4, p. 28-34, 1996. Disponível em: $<$ http://qnesc.sbq.org.br/online/qnesc04/pesquisa.pdf>. Acesso em: 19 out. 2016.

SILVEIRA JÚNIOR, C. da. A mediação docente da leitura de textos didáticos para o ensino e aprendizagem de ciências nos últimos anos do Ensino Fundamental. 2015. 236 f. Tese (Doutorado em Educação) - Faculdade de Educação, Universidade Federal de Minas Gerais, Belo Horizonte. 2015. Disponível em: < http://www.bibliotecadigital.ufmg.br/dspace/handle/1843/ BUBD-A3BG5K>.Acesso em: 30 set. 2016.

SILVEIRA JÚNIOR, C. da. Ler para aprender ligações químicas em aulas de ciências: investigação, reflexão e lições. 2012. 165 f. Dissertação (Mestrado em Educação) - Faculdade de Educação, Universidade Federal de Minas Gerais, Belo Horizonte. 2012. Disponível em: <http://www.bibliotecadigital.ufmg.br/dspace/ handle/1843/BUOS-966G62>._Acesso em: 24 out. 2014.

SILVEIRA JÚNIOR, C. da.; LIMA, M. E. C. C.; MACHADO, A. H. Leitura em sala de aula de ciências como uma prática social dialógica e pedagógica. Revista Ensaio, Belo Horizonte: FaE/UFMG: CECIMIG, v. 17, n. 3, p. 633-656, set./dez. 2015a. Disponível em: < http://www. scielo.br/scielo.php?pid=S1983-21172015000300633\&script $=$ sci_abstract\&tlng=pt $>$. Acesso em: 30 set. 2016.

SILVEIRA JÚNIOR, C. da.; LIMA, M. E. C. C.; MACHADO, A. H. Livro didático de ciências e a mediação da leitura de seus textos em sala de aula. Leitura: Teoria e Prática, Campinas, v. 33, n. 65, p. 53-69, 2015b. Disponível em: < https://ltp.emnuvens.com.br/ltp/article/view/411 >. Acesso em: 30 set. 2016. 
SMOLKA, A. L. B. A prática discursiva na sala de aula: uma perspectiva teórica e um esboço de análise. In: SIRGADO, A. P.; GÓES, M. C. R. (Org.). Cadernos Cedes 24 - Pensamento e linguagem: estudos na perspectiva da psicologia soviética. 3. ed. Campinas: Cedes, 2000. p. 51-65. SUISSO, C.; GALIETA, T. Relações entre leitura, escrita e alfabetização/letramento científico: um levantamento bibliográfico em periódicos nacionais da área de ensino de ciências. Ciência $\boldsymbol{\&}$ Educação, Bauru, v. 21, n. 4, p. 991-1009, 2015. Disponível em < http://www.scielo.br/scielo. php?pid=S1516-73132015000400013\&script=sci_abstract\&tlng=pt $>$. Acesso em: 28 set. 2016.

VIGOTSKI, L. S. Pensamento e linguagem. 4. ed. São Paulo: Martins Fontes, 2008.

VIGOTSKI, L. S. A construção do pensamento e da linguagem. São Paulo: Martins Fontes, 2001.

VIGOTSKI, L. S. A formação social da mente. 4. ed. São Paulo: Martins Fontes, 1991.

Recebido: 28/06/2015

Aprovado: 28/10/2016

\section{Contato:}

Ana Cristina Barbosa

Centro Federal de Educação Tecnológica de Minas Gerais (CEFET-MG), departamento de Química.

Av. Amazonas, 5253 - Nova Suíssa, Belo Horizonte, MG - Brasil. 30421-169

e-mail: acb.qui@gmail.com 